\section{Genetic Differences and Environmental Variations in Calyx-end Fruit Cracking among Japanese Persimmon Cultivars and Selections}

\author{
Masahiko Yamada and Akihiko Sato \\ Department of Grape and Persimmon Research, National Institute of Fruit \\ Tree Science, Akitsu, Hiroshima 729-2494, Japan
}

Yasuo Ukai ${ }^{1}$

Graduate School of Agricultural Life Sciences, University of Tokyo, Bunkyo-ku, Tokyo, 113, Japan

Additional index words. Diospyros kaki, calyx separation, fruit breeding, selection, genetics

\begin{abstract}
Environmental variance components were estimated for calyx-end fruit cracking in pollination-constant and nonastringent cultivars and selections of Japanese persimmon (Diospyros kaki Thunb.). The cracking value of a tree in a cultivar or selection (genotype) (X) was evaluated as the number of fruit that cracked divided by the total number (25) of fruit evaluated from each tree. Because the mean value of $X$ was correlated with the variance of $X$, analyses of variance were performed using its square root value. The variance associated with genotype $\times$ year interaction was the largest of environmental variance components. The variances associated among years and among trees within genotypes were very small. The mean percentage of cracked fruit in evaluation for 10 years was 3\% for 'Fuyu', $11 \%$ for 'Matsumotowase-Fuyu', and $12 \%$ for 'Izu'. On the basis of the environmental variance components obtained, it is proposed that all offspring genotypes exhibiting a phenotypic cracking incidence of less than $20 \%$ and $11 \%$ should be selected in single-year and three-year evaluations, respectively, when those genotypes are evaluated using 25 fruits from a single tree, in order to successfully select all genotypes with an genotypic incidence of less than $3 \%$.
\end{abstract}

Calyx-end fruit cracking is a type of cracking specific to Japanese persimmon (Diospyros kaki Thunb.), and is also called calyx separation ("Hetasuki" in Japanese) (Kitagawa and Glucina, 1984). Japanese persimmon cultivars are classified into two types, astringent and nonastringent, based on the presence or absence of astringency in the fruit at harvest. However, each type is further classified into two sub-types, variant- and constant-type, depending on the relationship between presence of seeds and flesh color (Yonemori et al., 2000). The flesh color of the variant-type becomes dark when it has seeds as a result of pollination, whereas the flesh color of the constant-type is not influenced by the presence of seeds. Horticulturally, Japanese persimmon cultivars are currently classified into the following fourtypes: pollination-constant, nonastringent (PCNA); pollination-variant, nonastringent (PVNA); pollination-constant, astringent (PCA); and pollination-variant, astringent (PVA) (Yonemori et al., 2000). Cultivars exhibiting cracking are common among PCNA cultivars including leading cultivars in Japan such as 'Fuyu'. However, there are very few cracking cultivars among the other type cultivars (Kajiura and Kawahara, 1934; Yamada et al., 1988; Yonemori et al., 2000).

Received for publication 16 Oct. 2000. Accepted for publication 17 May 2001.

${ }^{1}$ Retired.
Nonastringent persimmon cultivars including PCNA and PVNA types are mostly of Japanese origin (Yamada et al., 1994a; Yonemori et al., 2000). Nonastringent persimmons can be eaten while firm like an apple (Malus $\times$ domestica Borkh.) withoutpost-harvest treatment. However, the natural astringency loss is unstable in the PVNA type, depending on the number of seeds in the fruit. Astringent persimmons require artificial postharvest treatment to remove astringency. Conversely, the PCNA type gives stable, natural astringency loss when grown in warmer regions such as coastal areas south of lat. $36^{\circ} \mathrm{N}$ in Japan. Therefore, the PCNA type is the most desirable and its production has been increasing globally.

The cultivar improvement program of the National Institute of Fruit Tree Science (NIFTS) in Japan has been ongoing for more than 60 years. Its objective has been focused on developing superior PCNA cultivars (Yamada, 1993; Yamada et al., 1994b, 1995, 1997; Yonemori et al., 2000). The nonastringent trait of PCNA is recessive to the other astringent types, and almost no PCNA offspring were obtained from crosses among non-PCNA parents (Ikeda et al., 1985; Yamada, 1993; Yonemori et al., 2000). Therefore, crosses for obtaining PCNA offspring have been mostly conducted among PCNA cultivars and selections in the NIFTS breeding program.

Many existing PCNA cultivars crack, which has been a serious limitation in breeding
(Yamada, 1993; Yonemorietal.,2000). Yamada et al. (1988) reported that the inheritance of susceptibility to calyx-end cracking is controlled quantitatively, and cultivars that do not crack are homozygous recessive, whereas cultivars that crack are heterozygous. Crosses between cultivars that do not crack yield mostly noncracking offspring, and the number of offspring that crack is usually in proportion to the cracking severity of the parents. Therefore, crosses between PCNA cultivars inevitably produce a high percentage of offspring that crack.

The magnitude of cracking is highly environmentally influenced (Yamada et al., 1986; 1987), and the degree of cracking fluctuates greatly from year to year. Because of large yearly fluctuations, it is very difficult to precisely evaluate the genotypic value (Falconer, 1989) of a cultivar or selection. Also, persimmon trees are large and trials estimating the environmental variation of the trait are costly. The cultivaral difference in calyx-end fruit cracking has been reported using data evaluated for a single year or only a few years (Kajiura and Kawahara, 1934; Yamada et al., 1988). However, environmental influences were not evaluated in their reports, and the genetic property of individual cultivars or selections has not been clarified.

The objectives of our study were to: 1) estimate major environmental variance components for calyx-end fruit cracking; 2) evaluate the genetic differences in degree of the cracking through a 10-year evaluation of cultivars and selections that have been or will be used as parents in persimmon breeding; and 3) obtain an optimal critical cracking percentage for selecting genotypes with no or minimal cracking.

\section{Materials and Methods}

The study was conducted at the Dept. of Grape and Persimmon Research of the NIFTS, Akitsu, Hiroshima, Japan, using PCNA persimmon cultivars and selections. All trees were 14 years old in 1981 . The trees were normally grown with commercial cultural techniques in Japan (Yamada, 1994). The trees were annually pruned in winter; irrigated a few times in summer; fertilized; pestand disease-controlled; flowers were thinned before blossoming based on a 10 leaf : 1 flower ratio; and fruits were thinned in late July based on a 15-20 leaf : 1 fruit ratio.

Environmental variance estimation using five cultivars and selections, three single-tree replicates for 2 years. Calyx-end fruit cracking was evaluated for PCNA cultivars and selections 'Izu', 'Okugosho', 'Suruga', Okitsu-1, and Okitsu-25, using a sample size of 25 fully mature fruits with few exceptions, from each of three trees of each cultivar and selection (genotype) for 2 years (1981-82). "Cracking value" (X) of a single tree was defined as the number of fruit that cracked divided by the total number of fruit evaluated. Fruit cracking is a quantitative trait, and the critical degree of threshold cracking as to cracking or noncracking was that of Yamada et al. (1987) (Fig. 1). 


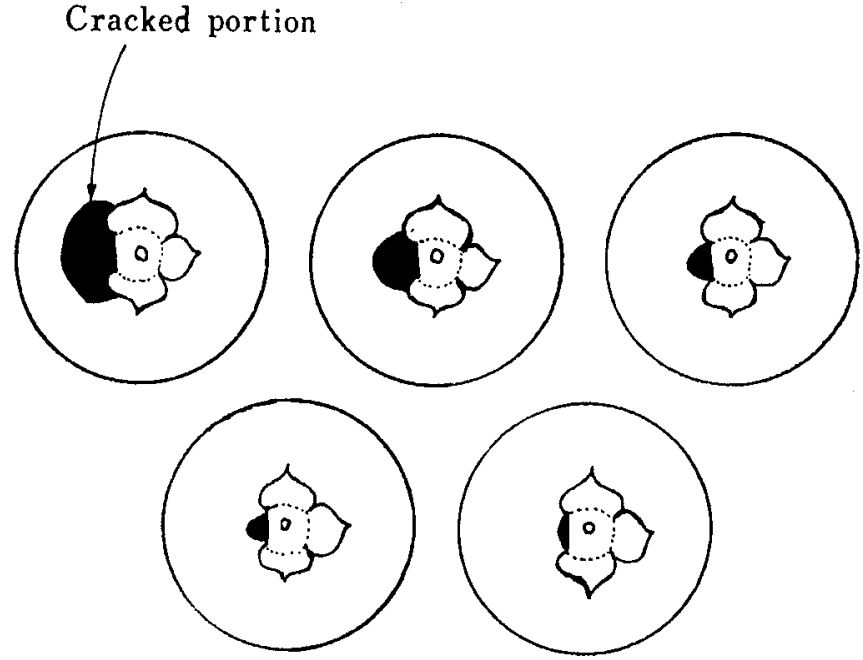

Fig. 1. Critical degree of threshold cracking as to cracking (upper three fruits) or noncracking (lower two fruits).

The model for the phenotypic cracking value $\left(\mathrm{P} 1_{\mathrm{ijk}}\right)$ of the jth tree of the ith genotype in the kth year is expressed as,

$$
\mathrm{P} 1_{\mathrm{ijk}}=\mu 1+\mathrm{g} 1_{\mathrm{i}}+\mathrm{t} 1_{\mathrm{ij}}+\mathrm{y} 1_{\mathrm{k}}+(\mathrm{gy} 1)_{\mathrm{ik}}+\mathrm{e} 1_{\mathrm{ijk}}
$$

where

$$
\begin{aligned}
\mu 1 & =\text { the overall mean, } \\
\mathrm{g} 1_{\mathrm{i}}= & \text { the genotypic effect of the } \\
& \text { ith genotype, } \\
\mathrm{t} 1_{\mathrm{ij}}= & \text { the effect of the jth tree of the } \\
& \text { ith genotype, } \\
\mathrm{y} 1_{\mathrm{k}}= & \text { the effect of the kth year, } \\
(\mathrm{gy} 1)_{\mathrm{ik}}= & \text { the effect of the interaction } \\
& \text { between the ith genotype } \\
& \text { and the kth year, } \\
\mathrm{e} 1_{\mathrm{ijk}}= & \text { the residual effect of the jth tree } \\
& \quad \text { of the ith genotype in the kth year. }
\end{aligned}
$$

Analysis of variance (ANOVA) provided the environmental variance component associated with among trees within genotypes $\left(\sigma_{t 1}^{2}\right)$, among years $\left(\sigma_{\mathrm{y} 1}^{2}\right)$, the genotype $\times$ year interaction $\left(\sigma_{\text {gyl }}^{2}\right)$, and the residual $\left(\sigma_{\mathrm{e} 1}^{2}\right)$. Before the ANOVA, the $X$ value was transformed into the square root value $(\sqrt{ } \mathrm{X})$. After transforming, the distribution of the residual was nonsignificant at $P=0.05$ using a one sample Kolmogorov-Smirnov test (Campbell, 1974), and it approximated a normal distribution. However, the arcsine-transformed $\mathrm{X}$ value was not applicable to the ANOVA.

Environmental variance estimation using 14 cultivars and selections and single trees for 10 years. The incidence of calyx-end cracking was evaluated for 14 PCNA cultivars and selections (genotypes), using a sample size of 25 fully mature fruits with few exceptions from a single tree for 10 years (1982-92, excluding 1991). The evaluation was carried out as described previously.

After transforming into a square root value, the phenotypic cracking values were subjected to ANOVA using the following model:

$$
P 2_{i j}=\mu^{2}+g 2_{i}+y 2_{j}+e 2_{i j}
$$

where
$\mathrm{P} 2_{\mathrm{ij}}=$ the phenotypic value of the ith genotype in the jth year,

$\mu 2=$ the overall mean,

$\mathrm{g} 2_{\mathrm{i}}=$ the effect of the ith genotype,

$y 2_{j}=$ the effect of the jth year,

$\mathrm{e} 2_{\mathrm{ij}}=$ the residual effect in the ith genotype of the jth year.

The correlation between the mean value and the variance over years in each genotype was significant for the original value $(r=0.87 * *)$ but nonsignificant for the transformed value $\left(r=0.15^{\mathrm{ss}}\right)$. After transformation, heterogeneity of the variance among years in each genotype was nonsignificant at $P=0.05$ using Bartlett's test (Campbell, 1974). The distribution of the residual estimates approximated a normal distribution at $P=0.05$ using a one sample Kolmogorov-Smirnov test. The ANOVA provided the variance associated with genotypes $\left(\sigma_{\mathrm{g} 2}^{2}\right)$, years $\left(\sigma_{\mathrm{y} 2}^{2}\right)$, and the residual $\left(\sigma_{\mathrm{e} 2}\right)$.

\section{Results and Discussion}

Environmental variance estimation using five cultivars and selections and three singletree replicates for 2 years. The ANOVA indicated the genotype $\times$ year interaction was significant $(P=0.01)$, but the effects of genotype, year, and tree were nonsignificant variance components in Expected MS.
$(P=0.05)$ (Table 1). The $\sigma_{\mathrm{gy} 1}^{2}, \sigma_{\mathrm{t} 1}^{2}, \sigma_{\mathrm{y} 1}^{2}$, and $\sigma_{\mathrm{e} 1}^{2}$ were estimated at $77.4 \times 10^{-3}, 0.9 \times 10^{-3}, 0$, and $13.1 \times 10^{-3}$, respectively ( $\sqrt{\mathrm{X}}$ value). The $\sigma_{\mathrm{e} 1}^{2}$ estimates the variance due to tree $\times$ year interaction and among-fruit samples within trees. The small $\sigma_{\mathrm{e} 1}^{2}$ obtained suggests the minimal effects of these factors. The significance of the genotype $\times$ year interaction and the very large value of its variance component estimate suggests that the genotype $\times$ year interaction was the largest environmental factor, although these results were obtained with a small number of degrees of freedom. Yamada et al. (1986) showed the year-to-year variation was very large compared to the variation due to fruit samples within trees, which parallels our findings.

By increasing the number of replications and years, the accuracy of the estimates for the cracking incidence of a genotype is increased. However, many reports (Kaltsikes, 1970; Mycroft, 1983; Patterson et al., 1977; Rasmussen and Lambert, 1961; Sekioka and Lauer, 1970; Shorter and Norman, 1983; Swallow and Wehner, 1989) showed that adding more locations, years, or both was more efficient than adding replications. Yamada et al. (1993) and Sato et al. (2000) also reported that an increase in replications was less efficient than that of yearly repetitions for evaluating fruit and berry traits in persimmon and grapes (Vitis sp.), respectively. Our results show a large $\sigma_{\text {gy } 1}^{2}$ and a very small $\sigma^{2}$, , suggesting that yearly repetition was effective for increasing accuracy compared with increasing tree replications.

Genetic difference and environmental variance estimation using 14 cultivars and selections and single trees for 10 years. The cracking value of a given cultivar or selection fluctuated greatly among years as the mean value for 10 years increased (Fig. 2). Okitsu25 showed a 0.47 mean cracking value for 10 years, with the cracking value among years greatly fluctuating, ranging from 0.08 to 0.89 . 'Fuyu' showed a mean of 0.03 for 10 years, varying from 0 to 0.11 among years.

'Fuyu', the leading commercial cultivar in Japan, had 0.03 as the mean value for 10 years, while 'Matsumotowase-Fuyu' and 'Izu', which are a midseason and early commercial cultivars, respectively, showed a value of 0.11 and 0.12 , respectively. The production of 'Hanagosho' ( 0.17 mean cracking value for 10 years) is limited to a small area in Japan partly due to its high percentage of cracking. The

Table 1. Analysis of variance (ANOVA) ${ }^{z}$ for calyx-end fruit cracking evaluation using five cultivars and selections (genotypes) with three trees per genotype for 2 years.

\begin{tabular}{lrll}
\hline Source of variation & df & \multicolumn{1}{c}{ MS } & \multicolumn{1}{c}{ Expected MS } \\
\hline Genotype & 4 & $0.0634^{\mathrm{Ns}}$ & $\sigma_{\mathrm{el}}^{2}+3 \sigma_{\mathrm{gy} 1}^{2}+2 \sigma_{\mathrm{t} 1}^{2}+6 \sigma_{\mathrm{g} 1}^{2}$ \\
Year & 1 & $0.0119^{\mathrm{Ns}}$ & $\sigma_{\mathrm{el}}^{2}+3 \sigma_{\mathrm{gy} 1}^{2}+15 \sigma_{\mathrm{y} 1}^{2}$ \\
Genotype $\times$ year & 4 & $0.2453^{* *}$ & $\sigma_{\mathrm{el}}^{2}+3 \sigma_{\mathrm{gy} 1}^{2}$ \\
Among trees within genotypes & 10 & $0.0148^{\mathrm{vs}}$ & $\sigma_{\mathrm{el}}^{2}+2 \sigma_{\mathrm{t1}}^{2}$ \\
Residual & 10 & 0.0131 & $\sigma_{\mathrm{el}}^{2}$ \\
\hline
\end{tabular}

${ }^{2}$ ANOVA was performed for the square root value $(\sqrt{X})$ of the cracking value $(X)$ of a tree. The cracking value of a tree in a genotype $(\mathrm{X})$ was evaluated as the number of the cracked fruit divided by the total number of fruit (25) evaluated from each tree. See the text for the symbols denoting

ss, ** Nonsignificant or significant at $P \leq 0.01$, respectively. 


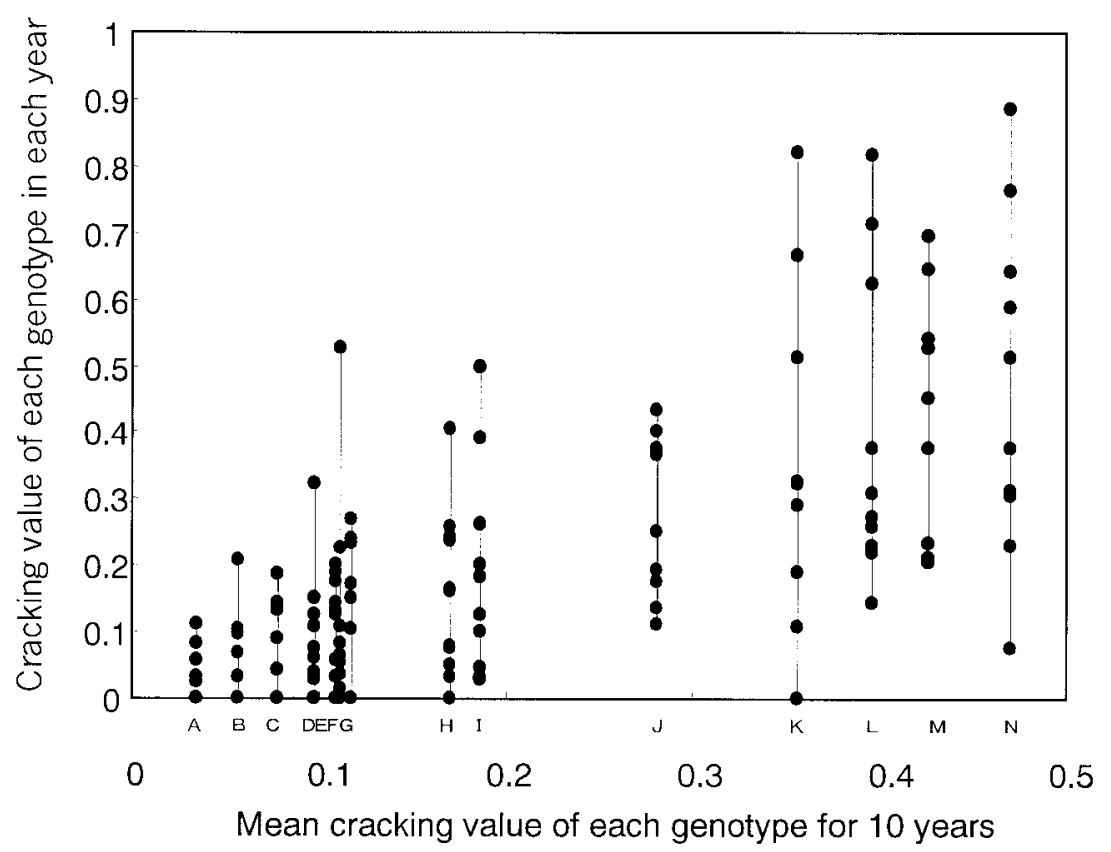

Fig. 2. Relationship between the mean cracking value over 10 years and the value in each year for 14 cultivars and selections. The cracking value was evaluated as the number of the cracked fruit divided by the total numer of fruit (25) evaluated, using a single-tree replicate. (A) 'Fuyu', (B) 'Izushiohgosho', (C) 'Tenjingosho', (D) ‘Okugosho', (E) 'Matsumotowase-Fuyu', (F) 'Suruga', (G) 'Izu', (H) 'Hanagosho', (I) F-2, (J) 'Okitsu-21, (K) Okitsu-24, (L) Okitsu-14, (M) Okitsu-1, and (N) Okitsu-25.

other cultivars listed in Table 2 are not commercially grown in Japan. Thus, a critical value in breeding at Akitsu can be set at $\approx 0.12$ for selecting genotypes that can be grown commercially based on the known-cultivar performance.

According to the ANOVA for the transformed values of 14 genotypes for 10 years, the effects of genotype and year were significant at $P=0.01$ (Table 3 ). The $\sigma_{\mathrm{e} 2}^{2}$ was large $\left(27.9 \times 10^{-3}\right)$, while the $\sigma^{2}{ }_{\mathrm{y} 2}$ was very small $\left(3.5 \times 10^{-3}\right)(\sqrt{\mathrm{X}}$ value $)$. The $\sigma_{\mathrm{e} 2}^{2}$ consists of the variance components due to the genotype $\times$ year interaction, the tree $\times$ year interaction, and among-fruit samples within tree replicates. The result of the first experiment, providing a large $\sigma_{\text {gyl }}^{2}$ and a small $\sigma_{\mathrm{e} 1}^{2}$, suggested that the $\sigma_{\mathrm{e} 2}^{2}$ was largely due to the genotype $\times$ year interaction.

The year-to-year variation generally includes the effect of year (among years), and the genotype $\times$ year interaction, and the tree $\times$ year interaction. The effect of year can be adjusted by the mean performance of several control cultivars and selections evaluated every year (Yamada et al., 1994c). Adjusting the year effect has been effective for reducing environmental bias in evaluating genetic property (Hansche and Brooks, 1965; Yamada et al., 1994b, 1994c, 1995, 1997). However, the genotype $\times$ year interaction and tree $\times$ year interaction cannot be adjusted easily. To reduce the environmental bias due to those interactions, the yearly repetition of measurement is effective, but costly.

Okuno et al. (1971) proposed a method in which principal component analysis was applied to the analysis of genotype $\times$ environment interaction. Applying this method to our data, no clear grouping of cultivars and selec-
Fruit cracking is generally related to water status in fruits and to the resistance of fruit skin to cracking (Abbott et al., 1986; Considine and Kriedemann, 1972; Glenn and Poovaiah, 1989; Kaneko et al., 1982; Lustig and Bernstein, 1985; Mirad and Shackel, 1992). It is possible, therefore, that the calyxend cracking may be affected by the time and quantity of rainfall in relation to the fruit growth pattern, which is presumably related to the fruit ripening time. However, in the principal component analysis, cultivars and selections showed no apparent groups that show any association with fruit ripening. Calyx-end fruit cracking may be also controlled by other additional factors.

The effect of year was small as reflected in the very small variance of $\sigma_{\mathrm{y} 2}^{2}$. No tree replication within a genotype was present in this experiment, therefore, the $\sigma_{\mathrm{g} 2}^{2}$ contained the variation among trees within genotypes, which was estimated to be very small in the first experiment. Disregarding the variations among trees, the genetic property of a genotype can be evaluated as the mean value for several years, with an error variance estimated by $\sigma_{\mathrm{e} 2}^{2}$.

Breeders should distinguish the genetic property of offspring as early as possible in selection. The error variance in evaluation obtained here provides a critical value in selection in a given measurement repetition. The upper one-tailed confidence limit at $P=$ $0.95(\mathrm{Y})$ of the cracking value of a genotype tions was recognized in a two-dimensional graph of the first and second principal components (data not shown).
Table 2. The mean and variance of the cracking value ${ }^{\mathrm{z}}$ (the original value) for 14 cultivars and selections (genotypes) evaluated for 10 years using a single tree.

\begin{tabular}{|c|c|c|c|c|}
\hline \multirow{2}{*}{$\begin{array}{l}\text { Cultivar and } \\
\text { selection }\end{array}$} & \multicolumn{2}{|c|}{ Cracking value } & \multirow[b]{2}{*}{ Origin } & \multirow{2}{*}{$\begin{array}{c}\text { Mean fruit } \\
w t^{\mathrm{y}}(\mathrm{g})\end{array}$} \\
\hline & Mean & Variance $\left(\times 10^{-3}\right)$ & & \\
\hline Fuyu & 0.03 & 2 & Native cultivar in Japan & 277 \\
\hline Izushiohgosho & 0.06 & 4 & Native cultivar in Japan & 226 \\
\hline Tenjingosho & 0.08 & 5 & Native cultivar in Japan & 289 \\
\hline Okugosho & 0.10 & 8 & Native cultivar in Japan & 232 \\
\hline Matsumotowase-Fuyu & 0.11 & 5 & Bud-sport of Fuyu & 245 \\
\hline Suruga & 0.11 & 26 & $\mathrm{~F}_{1}$ of Okugosho $\mathrm{x}$ Hanagosho & 270 \\
\hline Izu & 0.12 & 12 & $\mathrm{~F}_{1}$ of Okugosho $\times$ Okitsu-1 & 206 \\
\hline Hanagosho & 0.17 & 14 & Native cultivar in Japan & 229 \\
\hline $\mathrm{F}-2$ & 0.19 & 26 & $\mathrm{~F}_{1}$ of Jiro $x$ Okugosho & 211 \\
\hline Okitsu-21 & 0.28 & 14 & $\mathrm{~F}_{1}$ of Jiro $\mathrm{x}$ Tenjingosho & 329 \\
\hline Okitsu-24 & 0.36 & 63 & $\mathrm{~F}_{1}$ of Jiro $x$ Okitsu- $15^{\mathrm{x}}$ & 206 \\
\hline Okitsu-14 & 0.40 & 53 & $\mathrm{~F}_{1}$ of Okugosho $\mathrm{x}$ Hanagosho & 237 \\
\hline Okitsu-1 & 0.43 & 32 & $\mathrm{~S}_{1}$ of Okugosho & 172 \\
\hline Okitsu-25 & 0.47 & 63 & $\mathrm{~F}_{1}$ of Fuyu $\times \mathrm{F}-2$ & 185 \\
\hline
\end{tabular}

${ }^{2}$ The cracking value of a tree in a genotype $(\mathrm{X})$ was evaluated as the number of the cracked fruit divided by the total number of fruit (25) evaluated from each tree.

yThe mean fruit weight for fruit evaluated the calyx-end cracking.

${ }^{x} F_{1}$ of 'Okugosho' $x$ 'Hanagosho'.

Table 3. Analysis of variance (ANOVA) ${ }^{\mathrm{z}}$ for calyx-end fruit cracking evaluated using 14 cultivars and selections (genotypes) with a single tree per genotype for 10 years.

\begin{tabular}{lrccc}
\hline \hline Source of variation & df & MS & F & Expected MS \\
\hline Genotype & 13 & 0.3113 & $11.1^{* *}$ & $\sigma_{\mathrm{e} 2}^{2}+10 \sigma_{\mathrm{g} 2}^{2}$ \\
Year & 9 & 0.0774 & $2.8^{* *}$ & $\sigma_{\mathrm{e} 2}^{2}+14 \sigma_{\mathrm{y} 2}^{2}$ \\
Residual & 117 & 0.0279 & & $\sigma_{\mathrm{e} 2}^{2}$
\end{tabular}

${ }^{\mathrm{z}}$ ANOVA was performed for the square root value $(\sqrt{X})$ of the cracking value $(\mathrm{X})$ of a tree. The cracking value of a tree in a genotype (X) was evaluated as the number of the cracked fruit divided by the total number of fruit (25) evaluated from each tree. See the text for the symbols denoting variance components in expected MS.

${ }^{* * *}$ Significant at $P \leq 0.01$ 


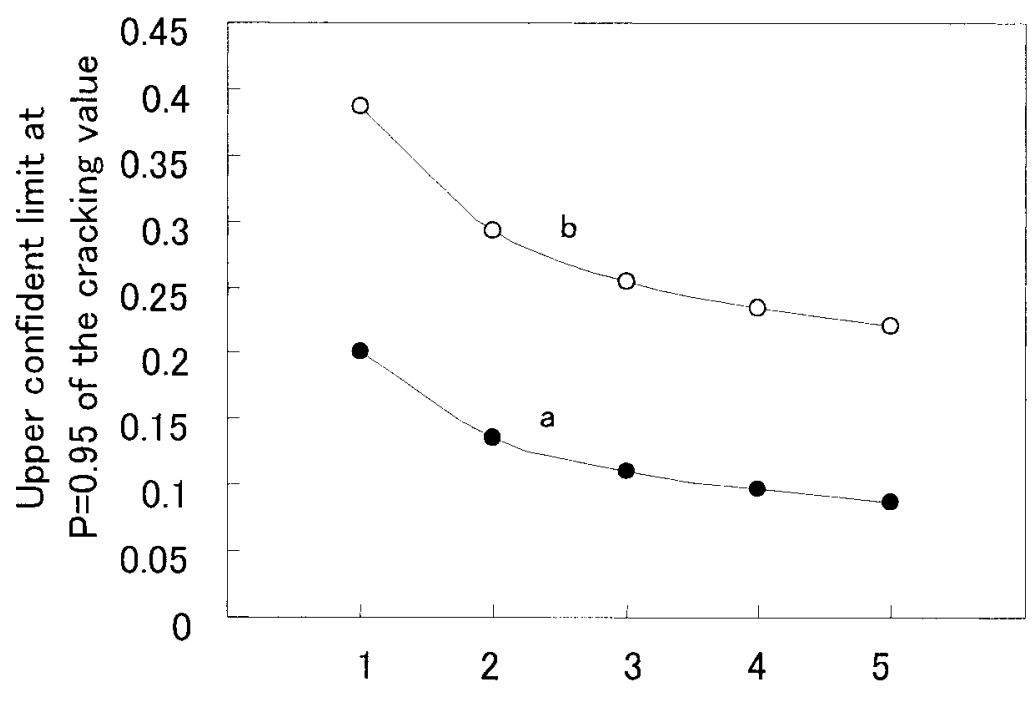

Number of years for repeating measurements

Fig. 3. The upper one-tailed confidence limit at $P=0.95$ (Y) of the cracking value of a genotype with the evaluation of 25 fruits from a single tree. Genotype value $\left(X_{G}\right)$ was assumed to be 0.03 (a) and 0.12 (b), respectively. $Y$ was calculated as follows: $\sqrt{ } \mathrm{Y}=\sqrt{X_{\mathrm{G}}}+1.645 \times \sqrt{ }\left(\sigma_{\mathrm{e} 2}^{2} / \mathrm{y}\right)$, where $\sigma_{\mathrm{e} 2}^{2}=$ the error variance and $\mathrm{y}=$ the number of years that the measurement is repeated.

evaluated using 25 fruits on a single tree for some years is as follows:

$$
\sqrt{ } \mathrm{Y}=\sqrt{ } \mathrm{X}_{\mathrm{G}}+1.645 \times \sqrt{ }\left(\sigma_{\mathrm{e} 2}^{2} / \mathrm{y}\right)
$$

where

$\mathrm{X}_{\mathrm{G}}=$ the genotypic value of a genotype, and

$\mathrm{y}=$ the number of years that the measurement is repeated.

In other words, a genotype having a genotypic value less than the $\mathrm{X}_{\mathrm{G}}$ is not expected to exhibit more than the $\mathrm{Y}$ at $P=0.95$. When a breeder desires to select genotypes having the genotypic value of $<0.03$ and 0.12 , which are the mean performance of 'Fuyu' and 'Izu' over 10 years, respectively, the critical value in selection should be set at the $\mathrm{Y}$ for $\mathrm{X}_{\mathrm{G}}=0.03$ and 0.12 , respectively. To select all genotypes having a genotypic cracking value $<0.03$, genotypes exhibiting a phenotypic cracking value of $<0.11$ and 0.20 should be all selected in the evaluation of measurements repeated for 3 years and without repeating yearly, respectively (Fig. 3 ). Similarly, to select genotypes with genotypic value of $<0.12$, genotypes exhibiting a phenotypic value $<0.26$ and 0.39 should be selected, respectively.

\section{Literature Cited}

Abbott, J.D., M.M. Peet, D.H. Willits, D.C. Sanders, and R.E. Gough. 1986. Effects of irrigation frequency and scheduling on fruit production and radial cracking in greenhouse tomatoes in soil beds and in a soil-less medium in bags. Scientia Hort. 28:209-217.
Campbell, R.C. 1974. Statistics for biologists. 2nd ed. Cambridge Univ. Press, U.K.

Considine, J.A. and P.E. Kriedemann. 1972. Fruit splitting in grapes: Determination of the critical turgor pressure. Aust. J. Agr. Res. 23:17-24.

Falconer, D.S. 1989. Introduction to quantitative genetics. 3rd ed. Longman, London.

Glenn, G.M. and B.W. Poovaiah. 1989. Cultivar properties and postharvest calcium applications influence cracking of sweet cherries. J. Amer. Soc. Hort. Sci. 114:781-788.

Hansche, P.E. and R.E. Brooks. 1965. Temporal and spatial repeatability of a series of quantitative characters in sweet cherry (Prunus avium L.). Proc. Amer. Soc. Hort. Sci. 86:120-128.

Ikeda, I., M. Yamada, A. Kurihara, and T. Nishida. 1985. Inheritance of astringency in Japanese persimmon. J. Jpn. Soc. Hort. Sci. 54:39-45.

Kajiura, M. and K. Kawahara. 1934. The incidence of fruit cracking at calyx and stylar ends in Japanese persimmon cultivars. J. Jpn. Soc. Hort. Sci. 5:129-132.

Kaltsikes, P.J. 1970. Genotype-environment interaction variances in yield trials of fall rye. Can. J. Plant Sci. 50:77-80.

Kaneko, T., M. Hashimoto, and A. Aoki. 1982 Relationship between the characteristics of fruit growth and fruit cracking in Japanese pear 'Kosui'. Bul. Tochigi Agr. Expt. Sta. 28:75-84.

Kitagawa, H. and P.E. Glucina. 1984. Persimmon culture in New Zealand. Sci. Info. Publ. Ctr., DSIR, Wellington, N.Z.

Lustig, I. and Z. Bernstein. 1985. Determination of the mechanical properties of the grape berry skin by hydraulic measurements. Scientia Hort. 25:279-285.

Mirad, R.E. and K.A. Shackel. 1992. Water relations of fruit end cracking in French prune (Prunus domestica L. cv. French). J. Amer. Soc. Hort. Sci. 117:824-828.

Mycroft,H. 1983. Variability of yields in cereal variety $\times$ fungicide trials. J. Agron. Sci. 100:535-538.
Okuno, T., F. Kikuchi, K. Kumagai, C. Okuno, M. Shiomi, and H. Tabuchi. 1971. Evaluation of varietal performance in several environments. Bul. Natl. Inst. Agr. Sci. Jpn. 18:93-147.

Patterson, H.D., V. Silvey, M. Talbot, and S.T.C. Weatherup. 1977. Variability of yields of cereal varieties in U.K. trials. J. Agr. Sci. 89:239-245.

Rasmussen, D.C. and J.W. Lambert. 1961. Variety $\times$ environment interactions in barley variety tests. Crop Sci. 1:261-262.

Sato, A., M. Yamada, H. Iwanami, and N. Hirakawa. 2000. Optimal spatial and temporal measurement repetition for reducing environmental variation of berry traits in grape breeding. Scientia Hort. 85:75-83.

Sekioka, T.T. and F.I. Lauer. 1970. Some estimates of genotype $\times$ environment interactions in potato variety tests. Amer. Potato J. 47:304-309.

Shorter, R. and R.J. Norman. 1983. Cultivar $\times$ environment interactions for kernel yield in Virginia type peanuts (Arachis hypogaea $\mathrm{L}$.) in Queensland. Aust. J. Agr. Res. 3:415-426.

Swallow, W.H. and T.C. Wehner. 1989. Optimum allocation of plots to years, seasons, locations and replications, and its application to onceover-harvest cucumber trials. Euphytica 43:5968.

Yamada, M. 1993. Persimmon breeding in Japan. Jpn. Agr. Res. Quarterly 27:33-37.

Yamada, M. 1994. Persimmon, p. 47-52. In: K. Konishi, S. Iwahori, H. Kitagawa, and T. Yakuwa (eds.). Horticulture in Japan. Asakura Co. Ltd., Tokyo.

Yamada, M., I. Ikeda, H. Yamane, and T. Hirabayashi. 1988. Inheritance of fruit cracking at the calyx end and stylar end in Japanese persimmon. J. Jpn. Soc. Hort. Sci. 57:8-16.

Yamada, M., H. Yamane, and T. Hirabayashi. 1986. Studies on crossbreeding of Japanese persimmon (Diospyros kaki Thunb.) 5. Variation of fruit cracking under calyx. Bul. Fruit Tree Res. Sta. E6: 11-20.

Yamada, M., H. Yamane, and T. Hirabayashi. 1987. Yearly fluctuations of two types of fruit cracking in seedling population of Japanese persimmon. J. Jpn. Soc. Hort. Sci. 56:287-292.

Yamada, M., H. Yamane, A. Sato, N. Hirakawa, and R. Wang. 1994a. Variations in fruit ripening time, fruit weight, and soluble solids content of oriental persimmon cultivars native to Japan. J. Jpn. Soc. Hort. Sci. 63:485-491.

Yamada, M., H. Yamane, Y. Takano, and Y. Ukai. 1997. Estimation of the proportion of offspring having soluble solids content in fruit exceeding a given critical value in Japanese persimmon. Euphytica 93:119-126.

Yamada, M., H. Yamane, and Y. Ukai. 1994b. Genetic analysis of Japanese persimmon fruit weight. J. Amer. Soc. Hort. Sci. 119:1298-1302.

Yamada, M., H. Yamane, and Y. Ukai. 1994c. Efficiency of use of control genotypes of reducing yearly fluctuations of quantitative fruit characters in Japanese persimmon. Bul. Fruit Res. Sta. 26:29-37.

Yamada, M., H. Yamane, and Y. Ukai. 1995. Genetic analysis of fruit ripening time in Japanese persimmon. J. Amer. Soc. Hort. Sci. 120:886890.

Yamada, M., H. Yamane, K. Yoshinaga, and Y. Ukai. 1993. Optimal spatial and temporal measurement repetition for selection in Japanese persimmon breeding. HortScience 28:838-841.

Yonemori, K., A. Sugiura, and M. Yamada. 2000. Persimmon genetics and breeding. Plant Breeding Rev. 19:191-225. 